\title{
Hyperpolarised Organic Phosphates as NMR Reporters of Compartmental pH
}

\author{
Jensen, Pernille Rose; Meier, Sebastian
}

Published in:

Chemical Communications

Link to article, DOI:

$10.1039 / \mathrm{C} 5 \mathrm{CC} 09790 \mathrm{H}$

Publication date:

2016

Document Version

Peer reviewed version

Link back to DTU Orbit

Citation $(A P A)$ :

Jensen, P. R., \& Meier, S. (2016). Hyperpolarised Organic Phosphates as NMR Reporters of Compartmental pH. Chemical Communications, 52, 2288-2291. https://doi.org/10.1039/C5CC09790H

\section{General rights}

Copyright and moral rights for the publications made accessible in the public portal are retained by the authors and/or other copyright owners and it is a condition of accessing publications that users recognise and abide by the legal requirements associated with these rights.

- Users may download and print one copy of any publication from the public portal for the purpose of private study or research.

- You may not further distribute the material or use it for any profit-making activity or commercial gain

- You may freely distribute the URL identifying the publication in the public portal

If you believe that this document breaches copyright please contact us providing details, and we will remove access to the work immediately and investigate your claim. 


\title{
Hyperpolarised Organic Phosphates as NMR Reporters of Compartmental $\mathrm{pH}^{\dagger}$
}

\author{
Pernille Rose Jensen ${ }^{a, b}$ and Sebastian Meier ${ }^{c^{*}}$
}

Organic phosphate metabolites contain functional groups with pKa values near the physiologic $\mathrm{pH}$ range, yielding $\mathrm{pH}$-dependet ${ }^{13} \mathrm{C}$ chemical shift changes of adjacent quaternary carbon sites. When formed in defined cellular compartments from exogenous hyperpolarised ${ }^{13} \mathrm{C}$ substrates, metabolites thus can yield localised $\mathrm{pH}$ values and correlations of organelle $\mathrm{pH}$ and catalytic activity.

Different $\mathrm{pH}$ values of cellular compartments help to maintain optimal conditions for the specialised biological processes occurring in these compartments. ${ }^{1}$ Normal catalytic functions are supported by compartmentalisation itself, which ensures controllable catalyst, substrate and ion (not least $\mathrm{H}^{+}$) concentrations. $^{2}$ Accordingly, abnormal $\mathrm{pH}$ homeostasis is detrimental to normal catalytic (metabolic) function in the cell.

Concurrent measurements of intracellular catalytic activities and physiological parameters such as $\mathrm{pH}$ permit direct correlations of biocatalytic function and physiological parameters. Nuclear magnetic resonance (NMR) spectroscopy is a non-invasive modality both for the detection of $\mathrm{pH}$ and for probing catalytic activities. The scope of NMR measurements has been extended by hyperpolarisation methods, which both improve the sensitivity (against the noise) and the selectivity (against the cellular background) of assays that most often detect non-protonated ${ }^{13} \mathrm{C}$ sites. ${ }^{3}$ These improvements are achieved by the temporary redistribution of nuclear magnetisation in exogenous substrates that are used as molecular probes with lifetimes of seconds. ${ }^{3}$ In the current study, we investigate the feasibility of instantaneous compartmental $\mathrm{pH}$ measurements with natural substrates through hyperpolarised NMR assays exploiting compartmentspecific catalytic activities. Using the example of the glycolytic reaction cascade, correlations of cytosolic $\mathrm{pH}$ and catalytic

\footnotetext{
a. Technical University of Denmark, Department of Electrical Engineering, Ørsteds Plads, Building 348, DK-2800 Kgs. Lyngby, Denmark

${ }^{b .}$ Albeda Research, Ole Maaløvs Vej 3, DK-2200 Copenhagen, Denmark

c. Technical University of Denmark, Department of Chemistry, Kemitorvet, Building

207, DK-2800 Kgs. Lyngby, Denmark.E-mail: semei@kemi.dtu.dk

+ Electronic Supplementary Information (ESI) available: Experimental details are collected in the ESI. See DOI: 10.1039/x0xx00000x
}

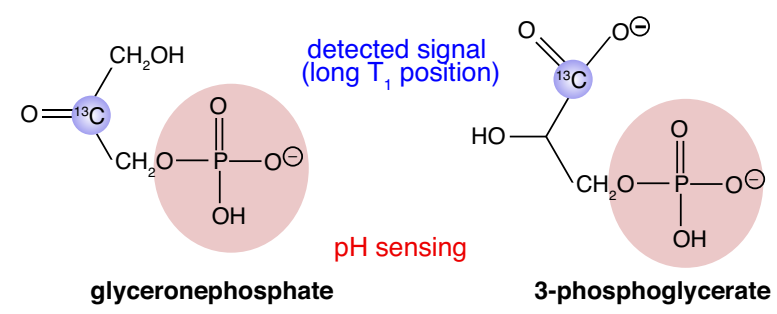

Fig. 1 Structures of glyceronephosphate and 3-phosphoglycerate, indicating long $\mathrm{T}_{1}$ positions (blue), whose chemical shifts are affected by phosphate groups sensing $\mathrm{pH}$ in the physiologic range (red) and whose long $\mathrm{T}_{1}$ times makes them suitable for hyperpolarised NMR detection.

activity are obtained: high-field NMR renders $\mathrm{pH}$-dependent signal changes in phosphorylated metabolites of the glycolytic reaction cascade detectable (Figure 1 ). At the same time, the signal amplitude of metabolites reflects the catalytic activity leading to their formation, thus permitting to correlate $\mathrm{pH}$ and catalyst activities with instantaneous measurements. The conversion of hyperpolarised endogenous substrates to metabolites reporting on physiological state $(\mathrm{pH})$ alleviates problems related to cell delivery, cell retention, entrapment in lysosomes via endocytosis and substrate toxicity. Notably, the subcellular $\mathrm{pH}$ measurements rely on non-invasive signal detection that has proven viable mammalian tissues. ${ }^{4}$

Various magnetic resonance approaches have been devised for the measurement of extracellular $\mathrm{pH}$ using ${ }^{1} \mathrm{H},{ }^{31} \mathrm{P}$ or ${ }^{19} \mathrm{~F}$ nuclei as $\mathrm{pH}$ indicators. ${ }^{5}$ Some problems relating to experimental duration and sensitivity as well as dose requirements have been addressed by hyperpolarised ${ }^{13} \mathrm{CNMR}$ using bicarbonate or Good's buffers as biocompatible $\mathrm{pH}$ indicators. ${ }^{6}$ As hyperpolarised NMR methods operate on the seconds timescale, the internalisation of molecular probes to intracellular sites has remained a challenge and equivalent approaches towards the study of intracellular $\mathrm{pH}$ by hyperpolarised NMR have been lacking. In contrast, phosphorylated endogenous metabolites and inorganic phosphate are well-established intracellular indicators for conventional ${ }^{31} \mathrm{P} N \mathrm{NMR}$. Even for highly concentrated cell suspension, such measurements accumulate thousands of scans and thus provide a coarse time average of $\mathrm{pH}$ over 

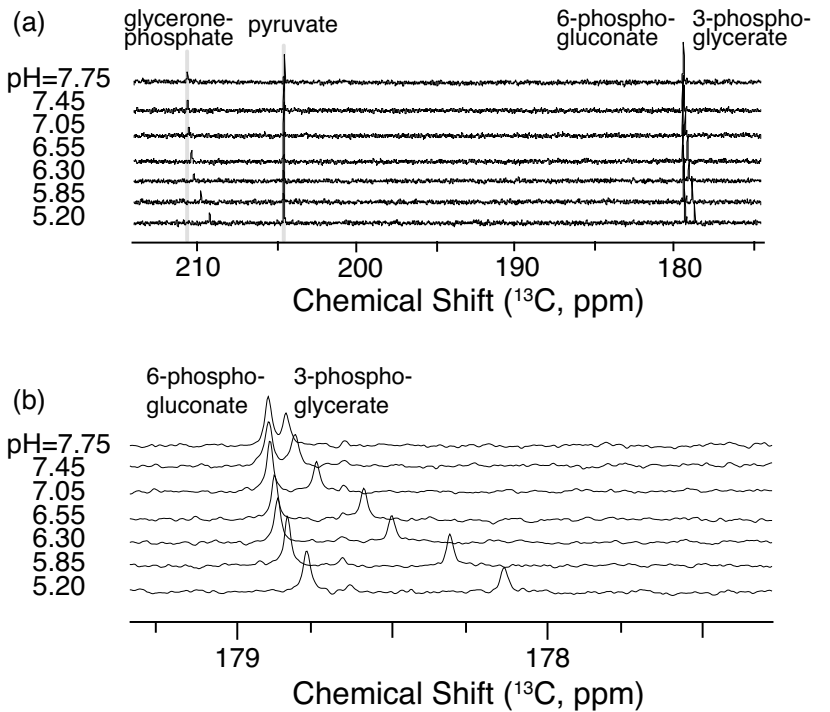

Fig. $2 \mathrm{pH}$ titration of a synthetic mixture of major glycolytic intermediates recorded by thermal ${ }^{13} \mathrm{C}$ NMR (top). Bottom: Blow-up of 6-phosphogluconate and 3-phosphoglycerate carboxyl group signals.

minutes or hours, while $\mathrm{pH}$ adaptations can occur within seconds. The extensive accumulation of ${ }^{31} \mathrm{P} N M R$ spectra is also not easily compatible with concurrent activity assays of cellular function. In addition, subtle $\mathrm{pH}$ differences are hard to detect as the signals are averaged over the entire cells and different metabolite pools can only be resolved for rather extreme $\mathrm{pH}$ differences in different compartments.

Hyperpolarised NMR probe molecules for the sensing of $\mathrm{Ca}^{2+}$ ions, $\mathrm{pH}$ and $\mathrm{H}_{2} \mathrm{O}_{2}$ have previously been designed by combining sensing groups and long $\mathrm{T}_{1}$ sites in the same molecule, ${ }^{7}$ but biological applications of these designed probes have remained challenging. Phosphorylated metabolites often contain quaternary ${ }^{13} \mathrm{C}$ nuclei with sufficiently long $\mathrm{T}_{1}$ times to render influx of hyperpolarised signal into the metabolite pool on the $T_{1}$ timescale detectable. As organic phosphates have pKa values near the physiological range, phosphorylated metabolites naturally combine long $\mathrm{T}_{1}$ sites and $\mathrm{pH}$ reporters in the same molecule (Figure 1). The formation of organic phosphates in cellular compartments thus potentially produces hyperpolarised $\mathrm{pH}$ probes.

In order to test the feasibility of hyperpolarised organic phosphates as $\mathrm{pH}$ indicators, the $\mathrm{pH}$ dependence of the $\delta^{13} \mathrm{C}$ chemical shifts was determined for a mixture of relevant reference standards with thermal ${ }^{13} \mathrm{C}$ NMR spectroscopy at 18.7 Tesla field strength (Figure 2). Principal intermediates accumulating in the glycolytic reaction cascade of various human, murine and microbial cell lines include glycerone phosphate, pyruvate, 3-phosphoglycerate and 6phosphogluconate. ${ }^{4,8}$ The phosphate group is located in the $\alpha$ position relative to the quaternary carbon in glycerone phosphate and in the $\beta$-position relative to the quaternary carbon in 3-phosphoglycerate. Thus, significant ${ }^{13} \mathrm{C}$ chemical shift changes in the physiological $\mathrm{pH}$ range are observed for the quaternary carbons of glyceronephosphate $\left(\delta^{13} \mathrm{C}_{\mathrm{pH} 7.5^{-}}\right.$ $\delta^{13} \mathrm{C}_{\mathrm{pH} 5.2} \approx 1.6 \mathrm{ppm}$ ) and 3-phosphoglycerate

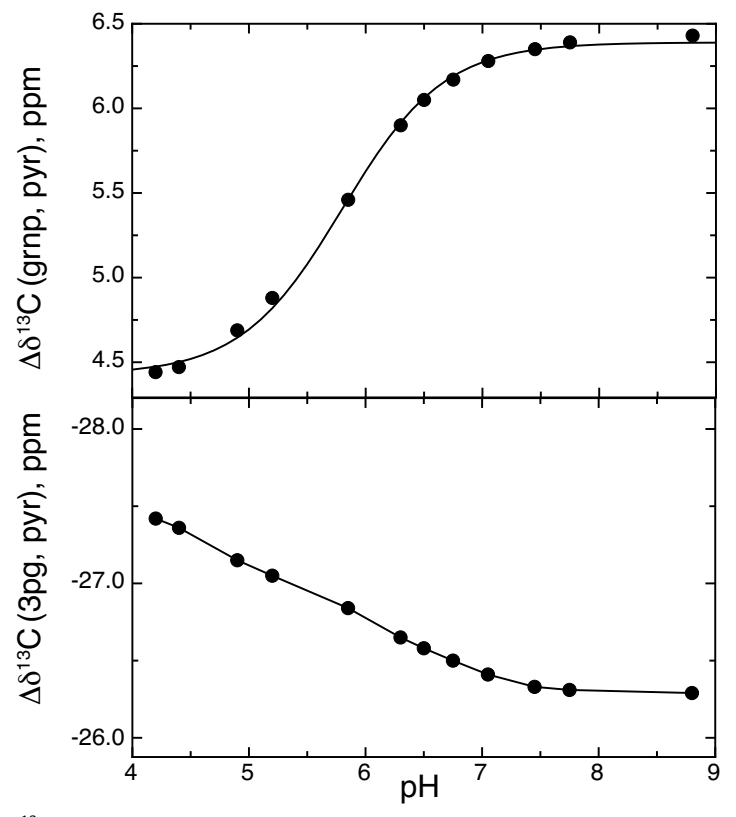

Fig. $3{ }^{13} \mathrm{C}$ Chemical shift differences relative to internal pyruvate (C2) for glyceronephosphate (C2, top) and 3-phosphoglycerate (C1,bottom) for the $\mathrm{pH}$ titration of Fig. 2.

$\left(\delta^{13} \mathrm{C}_{\mathrm{pH} 7.5}-\delta^{13} \mathrm{C}_{\mathrm{pH} 5.2} \approx 0.8 \mathrm{ppm}\right)$. In contrast, no significant ${ }^{13} \mathrm{C}$ chemical shift changes are detected for the keto and carboxylate group in pyruvate and for the carboxylate group of 6-phosphoglycerate. Pyruvate with a pKa of $2.5 \mathrm{ppm}$ provides an internal reference for relative chemical shift calibration that is $\mathrm{pH}$ invariant in the physiological $\mathrm{pH}$ range. Chemical shifts of glyceronephosphate $\mathrm{C} 2$ and 3-phosphoglycerate $\mathrm{C} 1$ are plotted relative to the pyruvate $\mathrm{C} 2$ signal in Figure 3 . As glyceronephosphate only contains one acid group (the phosphate), the chemical shift changes for glyceronephosphate were fitted to the Henderson-Hasselbalch equation to yield a $\mathrm{pH}$ calibration of

$$
\text { (1) } p H=p K_{a}+\log _{10} \frac{\Delta \delta_{o b s}-4.42 p p m}{6.39 p p m-\Delta \delta_{o b s}}
$$

with a pKa 5.81 and maximum and minimum chemical shift differences between glyceronephosphate and pyruvate of 6.39 and $4.42 \mathrm{ppm}$ at $30^{\circ} \mathrm{C}$ (Figure 3).

This calibration was used in determining $\mathrm{pH}$ values in yeast cells and to probe the effect of extracellular acidification on cytosolic

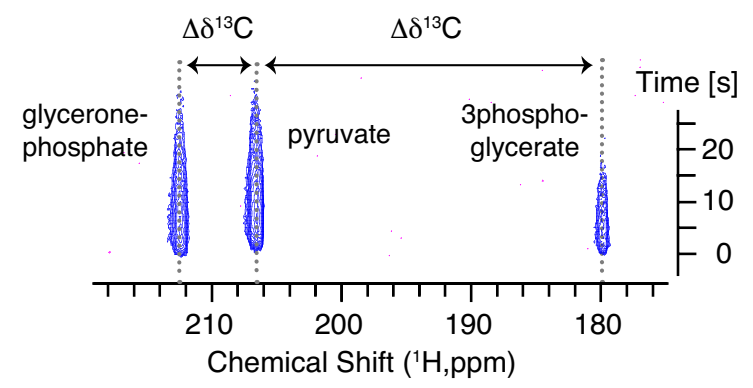

Fig. 4 Time series of the in vivo formation of hyperpolarised pyruvate, hyperpolarised $\left[\mathrm{U}_{-}{ }^{13} \mathrm{C}, \mathrm{U}^{2}{ }^{3} \mathrm{H}\right]$ glucose, yielding the $\mathrm{pH}$ dependent chemical shift differences of the signals. 
$\mathrm{pH}$ and catalytic activity in a well-studied model. Opposite to conventional ${ }^{31} \mathrm{P}$ NMR determinations, hyperpolarised organic phosphates are detectable almost instantaneously when using hyperpolarised carbohydrates as substrates (Figure 4). ${ }^{8 b, 8 c}$ The hyperpolarised NMR assays encompass very little averaging of the $\mathrm{pH}$ dependent signal position over time as spectra are acquired as single transients during an acquisition time of less than 0.3 seconds. In addition, spatial selectivity is warranted by the formation of the hyperpolarised organic phosphate $\mathrm{pH}$ indicator in defined compartments, here the cytosol.

Chemical shift changes of the glyceronephosphate signal relative to the pyruvate signal were detected upon extracellular acidification with weak organic acids (Figure 5a). Resultant chemical shift changes were translated to $\mathrm{pH}$ values with the parametrisation of equation (1). Cytosolic $\mathrm{pH}$ values determined in this manner are consistent with values determined previously by relative radioisotopic distributions of $\left[1-{ }^{14} \mathrm{C}\right]$ propionic acid to measure intracellular $\mathrm{pH}\left(\mathrm{pH}_{\mathrm{i}}\right)$ in yeast (Figure $\left.5 \mathrm{~b}\right) .{ }^{9}$ The decrease of cytosolic $\mathrm{pH}$ below the normal physiological range coincides with reduced catalytic activity in the glycolytic cascade (Figure $5 a)$. Less than $10 \%$ of the metabolic activity are retained after an intracellular $\mathrm{pH}$ decrease to $\mathrm{pH} 5.6$, in agreement with previous correlations of fermentation rate and radioisotopically determined $\mathrm{pH}_{\mathrm{i}}$ by Pampulha et al.. ${ }^{9}$ The detrimental changes to cytosolic fermentation kinetics at low $\mathrm{pH}$ include alterations that induce the accumulation of pernicious intermediates, as highlighted in Figure 5a. ${ }^{10}$

In concluding, we conduct high-field ${ }^{13} \mathrm{C} N M R$ measurements of hyperpolarised intracellular metabolites as prospective $\mathrm{pH}$ indicators. High-field NMR affords sufficiently accurate chemical shift measurements to identify cytosolic $\mathrm{pH}$ concurrently to

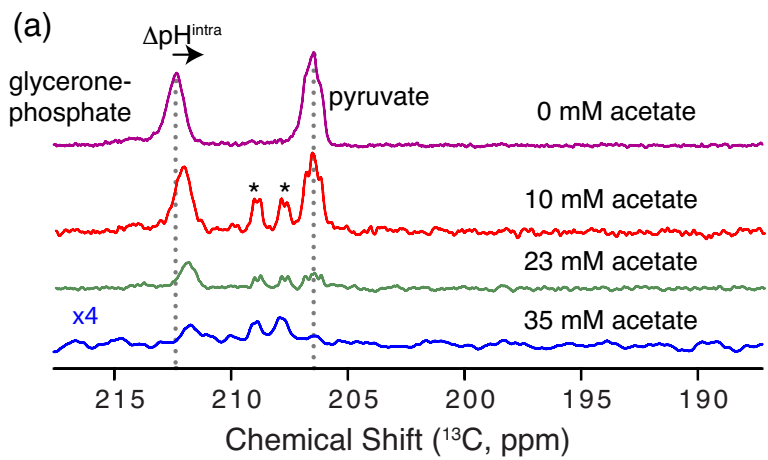

(b)

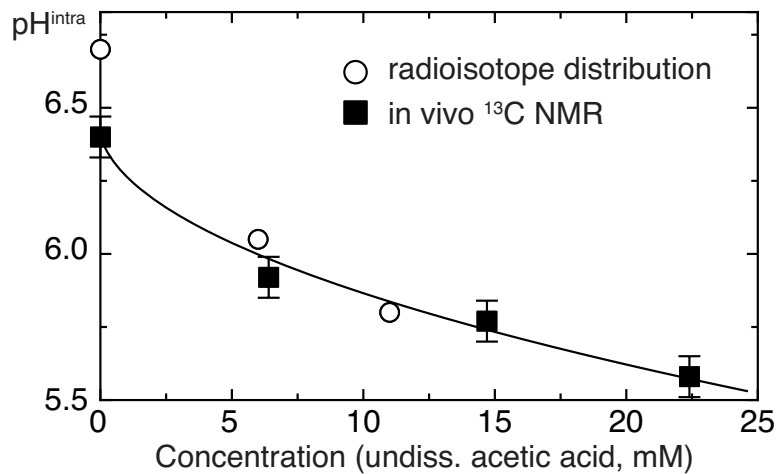

Fig. 5 (a) Sum spectra (0-20 seconds) of hyperpolarised metabolite formation at varying external acetate buffer concentrations of $\mathrm{pH} 4.5$. A change of the glyceronephosphate signal due to decreasing cytosolic $\mathrm{pH}$ at increasing acetic acid concentrations is evident, accompanied by decreasing biocatalytic activity. Asterisks indicate the accumulation of acetaldehyde intermediate upon determined $^{\text {s }}$ with relative radioisotopic distribution. catalytic activity in central carbon metabolism and to correctly reproduce correlations between cytosolic $\mathrm{pH}$ and catalytic activity. Cytosolic pH measurements using hyperpolarised ${ }^{13} \mathrm{C}$ chemical shifts of organic phosphates were extended to murine and human breast cancer cells ${ }^{8 \mathrm{e}}$ yielding cytosolic values of 6.90 , while corresponding determination for the bacterium Escherichia coli yielded an intracellular $\mathrm{pH}$ of $6.80 .^{8 \mathrm{c}}$ We note that the hyperpolarised ${ }^{13} \mathrm{C}$ NMR signal of glyceronephosphate has also been measured in a preclinical animal study of tumor glycolysis using hyperpolarised $\left[\mathrm{U}^{13}{ }^{13}, \mathrm{U}-{ }^{2} \mathrm{H}\right]$ glucose as the substrate. ${ }^{4}$ The use of alternative substrates with longer $\mathrm{T}_{1}$ times could facilitate the detection of intracellular organic phosphates with hyperpolarized NMR. As an example, hyperpolarized [2${ }^{13} \mathrm{C}$ ]-glycerone has recently allowed the detection of at least five different organic phosphate metabolites in a perfused liver model. ${ }^{11}$ These studies encourage the hope that rapid and noninvasive imaging of compartmental $\mathrm{pH}$ may become feasible through hyperpolarised ${ }^{13} \mathrm{C} \mathrm{NMR}$ of $\mathrm{pH}$ dependent metabolite signals.

P.R.J. gratefully acknowledges funding by the Danish National Research Foundation (grant DNRF124). S.M. gratefully acknowledges funding by grant 2013_01_0709 of the Carlsberg Foundation. $800 \mathrm{MHz}$ NMR spectra were recorded on the spectrometer of the Danish National Instrument Centre for NMR Spectroscopy of Biological Macromolecules at the Technical University of Denmark.

\section{Notes and references}

1 (a) J. Han and K. Burgess, Chemical Reviews, 2010, 110, 2709; (b) M. H. Lee, J. H. Han, J. H. Lee, N. Park, R. Kumar, C. Kang and J. S. Kim, Angew. Chem., Int. Ed., 2013, 52, 6206; (c) J. Llopis, J. M. McCaffery, A. Miyawaki, M. G. Farquhar and R. Y. Tsien, Proceedings of the National Academy of Sciences of the United States of America, 1998, 95, 6803.

2 D. E. Koshland, Science, 2002, 295, 2215.

3 J. H. Ardenkjaer-Larsen, B. Fridlund, A. Gram, G. Hansson, L. Hansson, M. H. Lerche, R. Servin, M. Thaning and K. Golman, Proc. Natl. Acad. Sci. USA, 2003, 100, 10158. T. B. Rodrigues, E. M. Serrao, B. W. Kennedy, D. E. Hu, M. I. Kettunen and K. M. Brindle, Nat. med., 2014, 20, 93. (a) R. J. Gillies, Z. Liu and Z. Bhujwalla, Am. J. Physiol. Cell Physiol., 1994, 267, C195; (b) S. Gil, P. Zaderenzo, F. Cruz, S. Cerdán and P. Ballesteros, Bioorg. Med. Chem., 1994, 2, 305; (c) Y. Aoki, K. Akagi, Y. Tanaka, J. U. N. Kawai and M. Takahashi, Invest. Radiol., 1996, 31; (d) S. Aime, A. Barge, D. Delli Castelli, F. Fedeli, A. Mortillaro, F. U. Nielsen and E. Terreno, Magn. Reson. Med., 2002, 47, 639; (e) A. M. Kenwright, I. Kuprov, E. De Luca, D. Parker, S. U. Pandya, P. K. Senanayake and D. G. Smith, Chem. Comm., 2008, 2514; (f) R. van Sluis, Z. M. Bhujwalla, N. Raghunand, P. Ballesteros, J. Alvarez, S. Cerdán, J.-P. Galons and R. J. Gillies, Magn. Reson. Med., 1999, 41, 743. (a) R. R. Flavell, C. von Morze, J. E. Blecha, D. E. Korenchan, M. Van Criekinge, R. Sriram, J. W. Gordon, H.Y. Chen, S. Subramaniam, R. A. Bok, Z. J. Wang, D. B. Vigneron, P. E. Larson, J. Kurhanewicz and D. M. Wilson, Chem. Comm., 2015, 51, 14119; (b) F. A. Gallagher, M. I. Kettunen, S. E. Day, D. E. Hu, J. H. Ardenkjaer-Larsen, R. Zandt, P. R. Jensen, M. Karlsson, K. Golman, M. H. Lerche and K. M. Brindle, Nature, 2008, 453, 940; (c) D. J. Scholz, 
A. M. Otto, J. Hintermair, F. Schilling, A. Frank, U. Kollisch, M. A. Janich, R. F. Schulte, M. Schwaiger, A. Haase and M. I. Menzel, Magma, 2015, 28, 591; (d) F. A. Gallagher, H. Sladen, M. I. Kettunen, E. M. Serrao, T. B. Rodrigues, A. Wright, A. B. Gill, S. McGuire, T. C. Booth, J. Boren, A. McIntyre, J. L. Miller, S.-H. Lee, D. Honess, S. E. Day, D.-E. Hu, W. J. Howat, A. L. Harris and K. M. Brindle, Cancer Res., 2015, 75, 4109; (e) R. K. Ghosh, S. J. Kadlecek, M. Pourfathi and R. R. Rizi, Magn. Reson. Med., 2015, 74, 1406.

7 H. Nonaka, R. Hata, T. Doura, T. Nishihara, K. Kumagai, M. Akakabe, M. Tsuda, K. Ichikawa and S. Sando, Nat.

Commun, 2013, 4.

8 (a) T. Harris, H. Degani and L. Frydman, NMR Biomed,, 2013, 26, 1831; (b) S. Meier, P. R. Jensen and J. O. Duus, FEBS Lett., 2011, 585, 3133; (c) S. Meier, P. R. Jensen and J. O. Duus, Chembiochem, 2012, 13, 308; (d) K. N. Timm, J. Hartl, M. A. Keller, E. Hu, M. I. Kettunen, T. B. Rodrigues, M. Ralser and K. M. Brindle, Magn. Reson. Med., 2014, DOI: 10.1002/mrm.25561.; (e) C. E. Christensen, M. Karlsson, J. R. Winther, P. R. Jensen and M. H. Lerche, J. Biol. Chem., 2014, 289, 2344.

9 M. E. Pampulha and M. C. Loureiro-Dias, Appl. Microbiol. Biotechnol., 1989, 31, 547.

10 P. R. Jensen, M. Karlsson, M. H. Lerche and S. Meier, Chemistry, 2013, 19, 13288.

11 K. X. Moreno, S. Satapati, R. J. DeBerardinis, S. C. Burgess, C. R. Malloy and M. E. Merritt, J. Biol. Chem., 2014, 289, 35859. 